\title{
COVID-19: Delayed Public Health Response Versus Great Need
}

\author{
Prof. Jens Holst* (iD) \\ Department of Nursing and Health Sciences, Fulda University of Applied Sciences, Germany
}

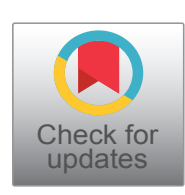

\begin{abstract}
No doubt, the COVID-19 crisis is offering particular opportunities and challenges for Public Health. In the beginning, the management of the pandemic was determined by virologists, supported by epidemiologists who did not always meet indispensable scientific requirements. Interdisciplinary and complex Public Health expertise failed to have tangible impact on the COVID-19 debate. This still questions the explicitly political nature of Public Health. The highly visible focus on biomedical responses and solutions counteracts its explicit socio-political character. Public Health is universal, complex and goes beyond health security. It must pay particular attention to the downstream and upstream determinants that led to the crisis, amely the political, economic, ecological and social conditions of health.
\end{abstract}

\section{The COVID-19 Public Health Threat}

A dangerous plague is sweeping the world. Public health experts and practitioners are utterly preoccupied by the COVID-19 infection rapidly unfolding around the globe. The pandemic threatens people's health and evokes dramatic consequences in numerous countries. One could assume that the world's dependence on effective interventions to slow down the spread of COVID-19 would underpin and increase the importance of Public Health [1,2]. However, the crisis rather exhibits the existing challenges of Public Health and the weakness of public health services. The long-term outcome of the COVID-19 crisis and the effect on Public Health remain therefore uncertain. Instead of strengthening Public Health, the current handling of the pandemic worldwide may rather become more of a challenge for Public Health.

Yet the COVID-19 pandemic has highlighted more clearly than ever the complex nature of Public (Global) Health. At the same time, it has revealed the extent to which biomedicine and biotechnology still dominate the debate. For weeks, politicians and the media continuously provided the populations in many countries around the world with a mix of meaningless epidemiological figures, threatening scenarios and deterrent images of overcrowded intensive care units. Apart from "Old" Public Health in the form of mainly national public health services, the voice of Public Health as theory and practice of protecting and improving people's health was hardly to be perceived during the first weeks of the COVID-19 pandemic. The Infodemics associated with the global spread of COVID-19 shows that the intrinsic complexity of Public Health failed to achieve sufficient impact in the media and general public [3].

The initial development around the pandemic made good science in the sense of "Old" Public Health being partly perverted even by a respected public-health institution, Johns Hopkins University in Baltimore, overwhelming the global public with ever new numbers of confirmed cases, deaths and recoveries [4]. Even the World Health Organization did not shy away from simply confronting and comparing absolute numbers among different countries and populations [5]. Presenting and publishing absolute figures without the slightest idea of what the reference values are runs counter to basic requirements of old public health. Meaningful epidemiological data require both a numerator and a denominator; However, the latter is either missing or, at best, inconclusive as there is an unknown number of unreported cases [6], and data about the number of tests realised are often piece work and incomplete. Moreover, even the numerator is doubtful due to a mix of under-reporting (people with or without symptoms who are not tested) and over-reporting (as not all patients who die with positive tests die from COVID-19).

In spite of all declarations about the relevance of Public health in a pandemic outbreak, it was not Public Health experts that became the second group to enter the scene after virologists and epidemiologists. Instead, economists and business experts were the second group creating awareness

*Corresponding author: Jens Holst, Department of Nursing and Health Sciences, Fulda University of Applied Sciences, Leipziger Strasse 123, D-36037, Fulda, Germany

Accepted: October 07, 2020

Published online: October 09, 2020

Citation: Holst J (2020) COVID-19: Delayed Public Health Response Versus Great Need. Ann Public Health Reports 4(1):65-69 
of economic consequences of lock-down decisions, and law experts warning about the deep cuts of civil and human rights. Only at a later stage did public health experts make a noticeable appearance.

\section{Biomedical Reductionism}

Recent experience during the early phases of the COVID-19 crisis has shown that the rapid succession of epidemic or pandemic outbreaks does not automatically contribute to shaping an awareness of Public Health. In contrast, the initial dominance of virologists and epidemiologists in media and political crisis management marginalised Public Health rather than strengthened it. The great importance decision makers attach to biomedical and biotechnical solutions compared to their determination to address social determinants of health is reflected in the huge amounts of money invested in developing COVID-19 vaccines [7] and the mega trial launched by WHO for accelerating the research on medicines to fight the current coronavirus pandemic [8]. Strikingly, there is no comparable research fund in sight for investigating the obviously relevant upstream determinants of the pandemic $[9,10]$.

COVID-19 is currently getting the full attention and distracting Public Health from existing long- and medium-term health crises [11]. The major threats facing today's world, the climate emergency, ecological degradation, armed conflicts, inequality, and a growing epidemic of non-communicable diseases fuelled by predatory commercial practices are being pushed to one side by COVID-19. For coming out "more recognized and strengthened", [1] Public Health must become more tangible and more politically committed.

In fact, the prevailing biomedical reductionism tends to supplant calls for more community health efforts [12], despite increasing evidence regarding the important role of socioeconomic and sociodemographic factors such as deprivation, population density, ethnicity, and chronic kidney disease, being associated with a higher likelihood of positive COVID-19 tests [13], and more severe outcomes [14,15]. Thus, the prevalent concentration of Public Health policies on both cross-border health problems and the spread of dangerous infectious diseases often lack an in-depth understanding of political, social and economic conditions and requirements [16]. Policies and health strategies are often lacking the intrinsic complexity and universality of Public Health, most recently in the context of the coronavirus pandemic, diverting the focus from the broad and universal approach of the Sustainable Development Goals.

\section{Implications for Future Public Health Strate- gies}

Public Health is increasingly determined by cross-border relations, policy priorities and particularly by security concerns; the securitisation of health is meanwhile considered a key feature of health governance [17]. Multiple agents at national and international levels interact to target and fight cross-border threats to health [18], as acute epidemic outbreaks are often regarded as predominant symptoms of globalisation. All too often, Public Health- as well as Global Health-pays less attention to potentially curable or preventa- ble long-term diseases like tuberculosis and obesity, and even less to the structural causes of bad health and health inequalities [19].

It is increasingly becoming obvious that the measures taken to fight the spread of COVID-19, particularly the lockdowns, are causing and will cause enormous social, economic and other indirect costs [20]. Recent OECD data show significant shrinkages of around 10-15 percent for most G20 countries, including such as France, Germany, Italy, Spain, the United Kingdom, and the United States [21,22].

However, the Gross Domestic Product and growth rates the OECD refer to is not telling the whole truth. The impact of recession is unequally distributed among and within societies. Unemployment is likely to rise to levels unheard of since the 1930's-deepening social divide and boosting authoritarian and nationalist movements and populist political parties. It will take several years to tally the total number of deaths, bankruptcies, layoffs, suicides, mental health problems, losses to income and investments, and other costs attributable not just to the virus but to the measures used to fight it. A mix of economic expertise, political requirements and social aspects provides increasingly convincing reasons for countries to begin easing their restrictions.

Meanwhile, after the rapid implementation of the lockdown, Public Health has hesitated too long and not fully used the potential to supply policymakers with sound, evidence-based practical recommendations of how to adjust the measures and reduce dubious decisions produced during the initial stage. Despite the persisting dearth of evidence on the efficacy or effectiveness of non-pharmaceutical interventions for pandemic outbreaks [23], a number of precipitous measures are rather questionable from a clinical and infectious point of view. As a matter of fact, the effect of travel restrictions as an isolated intervention is doubtful, at best [24], as evidence is lacking for its potential to contribute to the effective containment of infectious diseases [24]. Complete curfew prohibiting leaving the home except for very few cases, spending leisure time or doing sports outdoors is likely to be as exaggerated and ineffective as the complete closure of office buildings, in comparison with the implementation of the minimum requirements of physical distancing in order to maintain both recreational and labour activities. Likewise, more evidence is needed for underpinning the indiscriminate recommendation to use facial masks in the community as long as the general public is unaware of the correct use, minimum hygiene requirements are unknown and different types of masks with different levels of protection are available.

A sound, effective and successful strategy to fight a pandemic requires the multidisciplinary perspective of Public Health to provide robust evidence in order to prevent the negative effects from outweighing the positive. If Public Health is to be taken seriously, it must always address potential collateral damages of anti-pandemic strategies and monitor the undesired effects of the fight to contain the pandemic spread $[25,26]$. This will ultimately put the prevailing focus on health security into perspective. The COVID-19 pandemic has impressively revealed the trend to consider health security as 
a means for protecting the industry from the consequences of bad health rather than as a strategy for protecting people's health from infectious diseases, not to mention the harmful effect of industry on people's health [8]. Public Health has to go beyond health security and therefore question the ongoing securitisation of health in national and international policies.

\section{Politicising Instead of Securitising Public Health}

The desire for security is well understandable in an increasingly inequitable, unstable and frightening world. However, it often remains unclear what is meant by security, who defines security and how it is to be created. Security-oriented policies focus on safeguarding the status quo, however inequitable and unfair it may be as long as essential Public Health concerns such as pandemic outbreaks do not put social balance and integration across national borders in the forefront. Neglecting such crucial determinants of health threatens to undermine what politics should be geared to: The rights and legal entitlements of people, as laid down in human rights and in the WHO constitution. Unlike human rights, striving for security does not enforce the idea of universality. Current security strategies are not necessarily aimed at the protection of those who are most in need-the poor and the marginalised, whereas overcoming poverty, inequity and social injustice is key for social cohesion and better health and therefore a crucial objective of Public Health.

Instead of putting the actual causes of public health crises such as the social, economic and political determinants of health in the centre, the debate revolves on how to efficiently manage the crisis without having to tackle the underlying causes. Avoiding the question of how to combat risks at their origin, Public Health tends to focus on how to deal with future risks in such a way that they do not threaten the status quo or put vested interests at risk. New Public Health is largely concerned with the question of how to identify and contain the health problems resulting from the living and environmental conditions as early and far as possible [27]. However these upstream determinants of health are neither high on the health agenda, nor are political priorities, power relations or the influence of stakeholders [28].

Public Health is by no means immune to being instrumentalised for economic and political interests; it is rather interspersed with power relations [14], which health-related policies need to explicitly acknowledge [29]. Indeed, the existing power interests determine the predominant understanding of Public Health to a much greater extent than generally assumed or often discussed. The whole debate about public health governance, health system governance and governance for health [30] falls short in regard to analysing underlying power and power relations [29,31].

It has to be stressed that the root cause of the COVID-19 outbreak is not so much linked to the globalisation in itself but rather to the capability of transnational companies in imposing their business model thereby making microeconomic efficiency the lead dogma of global market economy. The prevailing economic system is man-made, and public policies worldwide, instead of prioritising national and social benefits, have accepted the predominance of transnational corporation profit interests' vis-à-vis macroeconomic efficiency or sustainable economic acting. Unemployment, vulnerability, socioeconomic inequalities and weakened public services, in particular the health services, are not problems in themselves but inevitable consequences of the dominant economic system. More equality requires the question of power and power relations to be put on the table. All attempts of the last forty years to change the prevailing economic model will inevitably clash with powerful players and vested interests, as it touches the core of today's worldwide economy, the unrestrained growth model and the distribution of resources.

\section{Resurgence of the Strong State}

However, the recent reactions to the COVID-19 crisis have exhibited an interesting policy shift: The resurgence of the strong state. Even the Financial Times, one of the world's leading business newspapers and certainly neither a progressive nor a very critical publication, states "Radical reforms - reversing the prevailing policy direction of the last four decades - will need to be put on the table. Governments will have to accept a more active role in the economy" [32]. The daily further underpins the need to "implement policies until recently considered eccentric, such as basic income and wealth taxes" [32]. Directly after these rather radical claims, however, the newspaper read by the richest and most powerful players in the globalised world, falls back into conservative thinking patterns when it comes to the conclusion that "redistribution will again be on the agenda" [32]. The increasingly accepted demand for redistribution does not go far enough; instead, the question of distribution must be addressed. The global reaction to the COVID-19 crisis must go beyond corrective interventions and retroactive compensations.

Taking the basic content and essential concerns of Public Health [33] seriously leads to the conclusion that, due to its explicit political nature, it cannot avoid getting involved in key social and societal questions such as the distribution of resources, equality of opportunities, political power relations, social justice, vested interests, human rights - all of them being relevant levers for people's health. In practice, Public Health policies all too often end up reproducing inequalities and perpetuating social injustice. This is particularly true for pandemics in past decades that have raised income inequality and exacerbated unemployment with widely disparate impact according to educational attainment. Long-lasting effects due to diminished employment prospects or job loss, other income shocks, lower remittances, and the resulting impoverishment are particularly tangible for those with only a basic education whereas people with advanced degrees are scarcely affected [34]. As this will further widen the existing socioeconomic gap in all countries and societies around the world, it definitely underpins the urgent and pressing need for effective universal health protection [35], including access to health care and the right to sick leave [36]. The COVID-19 outbreak dramatically stresses the necessity to set up a global social protection fund or similar financing mechanisms in order to allow particularly the low-income countries to protect 
their citizens from the immense costs of the current as well as of future pandemics [37].

The recent health security agenda, particularly the policies to fight infectious disease outbreaks such as COVID-19, has exhibited a twofold effect on public policies. One was the relapse into olden times in the form of a strong isolation of nation states even in those regions where integration had already reached a relatively high level or even appeared irreversible like in the European Union; the other was the at least short-term return of the strong state. After many years of spreading the neoliberal ideology and evicting the State from its responsibilities, the latter reasserted its claim to political control with surprising clarity and decisiveness. Governments decided to intervene in individual and social life and to restrict economic and entrepreneurial freedom. For protecting people's health, the lock-down and the interventions of the reinvigorated state appeared comprehensible, as they were scientifically justified.

The state's regained strength vis-à-vis the private sector and even transnational corporations should be basically maintained beyond the COVID-19 crisis. The state is the only authority capable of guaranteeing and enforcing the right to health as it ultimately the only one accountable for human rights violations [38]. For improving and safeguarding people's health, public policies must safeguard the human rights and legal entitlements of people. Public Health requires protecting those who are most in need - the poor and the marginalised - from health risks and bad health by overcoming poverty, inequities and social injustice. As important as good medical care is, it has less influence on people's health than their living, labour, income and environmental conditions, education, equal opportunities and social cohesion. Even in times of pandemic outbreaks, Public Health must consistently follow its broad socio-political approach instead of being deviated towards biomedical reductionism [39].

It would be detrimental to Public Health if researchers shy away from questioning the biomedical predominance in managing the pandemic or even from researching critical subjects outside the mainstream. In a world turned upside down due to a pandemic outbreak, it would be wrong to reduce Public Health to the search for medicines, vaccines and health security measures. Rather, it must advocate a health policy that addresses the social, economic, political and environmental causes of dangerous virus infections and all upstream determinants of health. In a nutshell, Public Health must first and foremost make a strong case for health-in-all policies. This will inevitably clash with powerful players and vested interests, as it touches the core of today's global economy, the prevailing growth model and ultimately the distribution of power. To emerge stronger and more visible from the current COVID-19 crisis, Public Health must become more explicit, more straightforward and ultimately more explicitly political.

\section{References}

1. Heymann D, Shindo N (2020) COVID-19: What is next for public health? Lancet 395: 542-545.

2. Martín-Moreno J (2020) Facing the COVID-19 challenge: When the world depends on effective public health interventions. SEEJPH XIV.DOI:10.4119/seejph-3442.

3. Nielsen N (2020) Coronavirus: Tech giants must stop Covid-19 'infodemic', saydoctors. EUObserver.

4. JHU (2020) COVID-19 dashboard by the center for systems science and engineering (CSSE). Baltimore: Johns Hopkins University.

5. World Health Organization (2020) Coronavirus disease (COVID-19) Dashboard. Geneva: WHO.

6. EbM Netzwerk (2020) COVID-19 - Where is the evidence? German network for evidence-based medicine website.

7. Schäferhoff M, Yamey G, McDade KK (2020) Funding the development and manufacturing of COVID-19 vaccines: The needfor global collective action. Washington DC: Brookings.

8. Kupferschmidt K, Cohen J (2020) WHO launches global mega trial of the fourmost promising coronavirus treatments. Science Mag.

9. Holst J (2020) Global health - emergence, hegemonic trends and biomedical reductionism. Globalization and Health 16: 42.

10. Horton R (2020) Offline: Don'tlet COVID-19 divert us completely. Lancet 395: 1534.

11. Michie S, West R (2020) Behavioural, environmental, social, and systems interventions against COVID-19. BMJ 370: m2982.

12. Aggleton $P$, Parker R (2015) Moving beyond biomedicalization in the HIV response: Implications for community involvement and community leadership among men who have sex with men and transgender people. Am J Publ Health 105: 1552-1558.

13. de Lusignan S, Dorward J, Correa A, et al. (2020) Risk factors for SARS-CoV-2 among patients in the Oxford royal college of general practitioners research and surveillance centreprimary care network: A cross-sectional study. Lancet Inf Dis 20: 1034-1042.

14. Chen T, Wu D, Chen H, et al. (2020) Clinical characteristicsof 113 decease dpatients with coronavirus disease 2019: Retrospective study. BMJ 368: 1091.

15. Ho FK, Celis-Morales CA, Gray SR, et al. (2020) Modifiableand non-modifiable riskfactors for COVID-19: Results from UK Biobank. MedRxiv.

16. Chan O (2020) COVID-19 is a wake-up call for public health preparedness in the climate crisis. New York: The Century Foundation.

17. Labonté R, Gagnon M (2010) Framing health and foreign policy: Lessons for global health diplomacy. Globalization Health 6:14.

18. Bengtsson L, Rhinard M (2018) Securitisation across borders: The case of 'health security' cooperation in the European Union. West European Politics 42: 346-368.

19. Yong K, Shakow A, Mate K, et al. (2005) Limited good and limited vision: Multidrug-resistant tuberculosis and global healthpolicy. SocSci Med 61: 847-859.

20. Karlson Nils, Stern Charlotta, Klein Daniel (2020) Sweden's coronavirus strategy will soon be the world's herd immunity is the only realistic option - the question is how to get there safely. Foreign Affairs.

21. Organisation for Economic Co-operation (2020) OECD policy responses to coronavirus (Covid-19). Evaluating the initial impact of COVID-19 containment measures on economic activity. Paris.

22. Organisation for Economic Co-operation (2020) Economic outlook 2020. Paris. 
23. Aledort J, Lurie N, Wasserman J, et al. (2007) Non-pharmaceutical public health interventions for pandemic influenza: An evaluation of the evidence base. BMC Public Health 7: 208.

24. Errett N, Sauer L, Rutkow L (2020) Integrative review of the limited evidence on international travel bans as an emerging infectious disease disaster control measure. J Emerg Manag 18: 7-14.

25. Norton A, de la Horra Gozalo A, Feune de Colombi N, et al. (2020) The remaining unknowns: A mixed methods study of the currentand global health research priorities for COVID-19. BMJ Glob Health 5: e003306.

26. Dobson A, Pimm S, Hannah L, et al. (2020) Ecology and economics for pandemic prevention. Science 369: 379-381.

27. Mateus A, Otete H, Beck C, et al. (2020) Effectiveness of travel restrictions in the rapid containment of human influenza: $A$ systematic review. Bull World Health Organ 92: 868-880.

28. Foldspang A (2015) Towards a public health profession: The roles of essential public health operations and lists of competences. Eur Journal Publ Health 25: 361-362.

29. Moon S (2019) Power in global governance: An expanded typology from global health. Globalization and Health 15: 74.

30. Shiffman J (2015) Global healthas a field of power relations: A response to recent commentaries. Int J Health Policy Manag 4: 497-499.
31. Greer S, Wismar M, Figueras J (2020) Strengthening health system governance. betterpolicies, stronger performance. Open University Press McGraw-Hill Education. Berkshire, England.

32. Galeo S (2018) Power and Public Health. Boston: University School of Public Health.

33. (2020) Virus lays bare thefrailtyofthesocialcontract. Radical reforms are required to forge a society that will workfor all. Financial Times.

34. Greer S, Bekker M, Evelyne de Leeuw E, et al. (2017) Policy, politics and public health. Eur J Public Health 27: 40-43.

35. Furceri D, Loungani P, Ostry J (2020) How pandemics leave the poor even farther behind. Washington DC: IMF.

36. Furceri Davide, Loungani Prakash, Ostry Jonathan, et al. (2020) COVID-19 will raise inequality if past pandemics are a guide. VOX CEPR Policy.

37. Yates $R$ (2020) In the era of Covid-19 healthcare should be universal and free. Mail \& Guardian.

38. Heymann J, Raub A, Waisath W, et al. (2020) Protecting health during COVID-19 and beyond: A global examination of paid sick leave design in 193 countries. Glob Public Health 15: 925-934.

39. Friedman E, Gostin L, Maleche A, et al. (2020) Global Health in the Age of COVID-19: Responsive Health Systems Through a Right to Health Fund. Health and Hum Rights.

DOI: $10.36959 / 856 / 495$ 